\title{
Potential Application of Hydrogen in Traumatic Injury
}

\section{Xiao Zhai and Xue Jun Sun*}

Department of Diving Medicine Second Military Medical University Shanghai, China

Hydrogen gas $\left(\mathrm{H}_{2}\right)$ was first practiced to prevent decompression sickness [1]. Fundamental researches showed that produced in electrolyzed-reduced water, hydrogen protects DNA from oxidative damage in 2007, Ohsawa et al. [2] showed that $\mathrm{H}_{2}$ has therapeutic antioxidant activity and ameliorates cerebral ischemia/reperfusion (I/R) injury, by selectively reducing cytotoxic Reactive Oxygen Species (ROS), ONOO- and • $\mathrm{OH}$ [2]. Multiple studies on different models were then carried out, such as intestinal I/R injury [3] neonatal cerebral hypoxia-ischemia [4] pulmonary hypertension [5], liver injury [6] and lung injury [7], supporting the above hypothesis.

Trauma remains the leading to death in Americans [8]; yet few treatments are proven effective, especially on brain damage and overall system [9]. A growing number of studies proved that hydrogen also ameliorates trauma induced inflammation and apoptosis. For traumatic brain injury, Hou et al. [10] suggested that hydrogen-rich saline conveniently protects the brain on cognition and synaptic plasticity with significantly less brain edema, lesion size and neurological deficiencies than rats that did not inhale $\mathrm{H}_{2}$, owing to its capability to across blood-brain barrier [10]. For acute spinal cord contusion injury, Chen et al. [11] stated that hydrogen reduced oxidative stress while elevating of BDNF. And in recent report, Ren et al. [12] found that against traumatic pancreatitis in a rats, $\mathrm{H}_{2}$-rich saline produced a distinct protection, and enrolled endogenous antioxidants in pancreas, such as glutathione and superoxide dismutase [13].

Due to a characteristic of safety and abundance in the universe, hydrogen is believed to translate to clinical application in the near future. However, further mechanisms need to be predominantly investigated. Taken together, the potential of $\mathrm{H}_{2}$-rich saline was highlighted as a novel therapeutic agent on trauma injury [14].

\section{References}

1. Cai J, Kang Z, Liu WW, Luo X, Qiang S, et al. (2008) Hydrogen therapy reduces apoptosis in neonatal hypoxia-ischemia rat model. Neurosci Lett 441: 167-172.

2. Ohsawa I, Ishikawa M, Takahashi K, Watanabe M, Nishimaki K, et al. (2007)
Hydrogen acts as a therapeutic antioxidant by selectively reducing cytotoxic oxygen radicals. Nat Med 13: 688-694.

3. Eckermann JM, Krafft PR, Shoemaker L, Lieberson RE, Chang SD, et al (2012) Potential application of hydrogen in traumatic and surgical brain injury, stroke and neonatal hypoxia-ischemia. Med Gas Res 2: 11

4. Fontanari $\mathrm{P}$, Badier $\mathrm{M}$, Guillot $\mathrm{C}$, Tomei $\mathrm{C}$, Burnet $\mathrm{H}$, et al. (2000) Changes in maximal performance of inspiratory and skeletal muscles during and after the 7.1-MPa Hydra 10 record human dive. Eur J Appl Physiol 81: 325-328.

5. Fukuda K, Asoh S, Ishikawa M, Yamamoto Y, Ohsawa I, et al. (2007) Inhalation of hydrogen gas suppresses hepatic injury caused by ischemia/reperfusion through reducing oxidative stress: Biochem Biophys Res Commun, 361: 670674

6. Shirahata S, Kabayama S, Nakano M, Miura T, Kusumoto K, et al. (1997) Electrolyzed-reduced water scavenges active oxygen species and protects DNA from oxidative damage. Biochem Biophys Res Commun 234: 269-274.

7. Huang CS, Kawamura T, Toyoda Y, Nakao A (2010) Recent advances in hydrogen research as a therapeutic medical gas. Free Radic Res 44: 971-982.

8. Mao YF, Zheng XF, Cai JM, You XM, Deng XM, et al. (2009) Hydrogen-rich saline reduces lung injury induced by intestinal ischemia/reperfusion in rats. Biochem Biophys Res Commun 381: 602-605

9. Dutton RP, Stansbury LG, Leone S, Kramer E, Hess JR, et al. (2010) Trauma mortality in mature trauma systems: are we doing better? An analysis of trauma mortality patterns, 1997-2008. J Trauma 69: 620-626.

10. Hou Z, Luo W, Sun X, Hao S, Zhang $Y$, et al. (2012) Hydrogen-rich saline protects against oxidative damage and cognitive deficits after mild traumatic brain injury: Brain Res Bull, 88: 560-565.

11. Chen C, Chen Q, Mao Y, Xu S, Xia C, et al. (2010) Hydrogen-rich saline protects against spinal cord injury in rats. Neurochem Res 35: 1111-1118.

12. Ren J, Luo Z, Tian F, Wang Q, Li K, et al. (2012) Hydrogen-rich saline reduces the oxidative stress and relieves the severity of trauma-induced acute pancreatitis in rats. J Trauma Acute Care Surg 72: 1555-1561.

13. Wang SB, Tian S, Yang F, Yang HG, Yang XY, et al. (2009) Cardioprotective effect of salvianolic acid $A$ on isoproterenol-induced myocardial infarction in rats. Eur J Pharmacol 615: 125-132.

14. Zheng X, Mao Y, Cai J, Li Y, Liu W, et al. (2009) Hydrogen-rich saline protects against intestinal ischemia/reperfusion injury in rats. Free Radic Res 43: 478484
*Corresponding author: Xuejun Sun, Department of Diving Medicine, Second Military Medical University, 800 Xiangyin Rd, Shanghai 200433, China, Tel: 13816390582; E-mail: sunxjk@hotmail.com

Received September 25, 2013; Accepted September 27, 2013; Published September 30, 2013

Citation: Zhai X, Sun XJ (2013) Potential Application of Hydrogen in Traumatic Injury. J Trauma Treat 3: e116. doi:10.4172/2167-1222.1000e116

Copyright: (c) 2013 Zhai X, et al. This is an open-access article distributed unde the terms of the Creative Commons Attribution License, which permits unrestricted use, distribution, and reproduction in any medium, provided the original author and source are credited. 